\title{
Space-time localization probability of enhanced seismic hazard in LURR medium-term prediction technique as applied to New Zealand territory
}

D. P. Kovalev

P. D. Kovalev

K. V. Kirillov
Institute of Marine Geology and Geophysics, FEB RAS, Yuzhno-Sakhalinsk, Russia

\begin{abstract}
A review of the results obtained based on long-term observations of hydro- and meteorological parameters, carried out for many years IMGG FEB RAS. One of the main objectives of the research field of the wave variability in the coastal zone is the experimental study of marine hazards in the coastal zone, which may represent a serious threat to the coastal settlements. IMGG FEB RAS holds the full cycle investigations of wave parameters at the coastal area till the creation of instruments to the measurement and software systems for the analysis of the results to the direct analysis of the field data.
\end{abstract}

\section{Keywords}

Marine hazards, Tyagun, Seiche, Infragravity waves

\section{$\underline{\text { References }} \underset{\AA_{\mathrm{PDF}}}{\underline{f_{0}}}$}

For citation: Kovalev D.P., Kovalev P.D., Kirillov K.V. The investigation of dangerous marine phenomena in the coastal zone based on the field observations results. Geosystems of Transition Zones, 2017, vol. 1, N 2, p. 18-34. doi:10.30730/2541-8912.2017.1.2.018-034 